\title{
Role of Keratinocytes in Human Recurrent Herpetic Lesions Ability to Present Herpes Simplex Virus Antigen and Act As Targets for T Lymphocyte Cytotoxicity In Vitro
}

\author{
A. L. Cunningham and J. R. Noble \\ Virology Unit, Institute of Clinical Pathology and Medical Research, Westmead Hospital, Westmead 2145, N.S.W. Australia
}

\begin{abstract}
In human recurrent herpetic lesions epidermal keratinocytes are induced to express HLA class II (DR) antigens. Keratinocytes derived from human split skin and cultured in vitro were induced to express HLA-DR but not -DQ antigens with IFN gamma preparations. These stimulated keratinocytes presented herpes simplex antigen directly to autologous blood-derived $T$ lymphocytes in four of four subjects (stimulation indices: 1.5-2.7), suggesting that keratinocytes may have an accessory herpes simplex virus (HSV) antigen-presenting role in addition to the Langerhans cells and macrophages in herpetic skin lesions. Blood mononuclear cells from eight herpes simplex seropositive subjects which were activated in vitro by HSV antigen for $6 \mathrm{~d}$ showed cytotoxicity specific for HSV in infected autologous keratinocytes. This was significantly increased by prestimulation with IFN gamma (51-56\% to 83-85\%). In four of eight patients some cytotoxicity also occurred against uninfected, IFN gamma-stimulated keratinocytes. Lymphocyte subset analysis showed that cytotoxicity against HSV-infected, IFN gamma-stimulated keratinocyte targets was mediated by both CD3 $+\mathrm{T}$ lymphocytes and Leu $11 \mathrm{~b}+$ natural killer cells. $T$ lymphocyte cytotoxicity was mediated by both CD4+ and CD8 + T lymphocytes, suggesting a cytotoxic role for the activated CD4+ lymphocytes that initially predominate in herpetic lesions.
\end{abstract}

\section{Introduction}

The humoral and cellular immune responses to primary herpes simplex infection have been extensively studied in rodents and humans. Animal models have been particularly useful in primary infection but they have not been as close an approximation to human recurrent disease (summarized in reference 1). The predominant immune cell types in recurrent herpes simplex lesions were recently described (2). Serial biopsies of lesions from 0.5 to $6 \mathrm{~d}$ after onset demonstrated early infiltration of $\mathrm{CD} 4$ positive $\mathrm{T}$ lymphocytes and Leu M3 positive monocyte/macrophages into subepidermal and perivascular regions of the dermis. The normalization of CD4/CD8 lymphocyte ratios in skin after 2-3 d suggested a later influx of CD8 positive $T$ lymphocytes. Leu $11+$ natural killer cells were

This work was presented at the 12 th International Herpesvirus Workshop, Philadelphia, PA, 30 July 1987.

Address reprint requests to Dr. A. L. Cunningham, Virology Unit, I.C.P.M.R., Westmead Hospital, Westmead 2145 N.S.W., Australia.

Received for publication 25 April 1988 and in revised form 17 August 1988.

J. Clin. Invest.

(C) The American Society for Clinical Investigation, Inc.

0021-9738/89/02/0490/07 \$2.00

Volume 83, February 1989, 490-496 underrepresented in the dermal infiltrates (1-4\%) and B lymphocytes were rare. Epidermal keratinocytes within and adjacent to the papule, vesicle or crust expressed HLA-DR antigens and this became uniform within $2 \mathrm{~d}$. IFN-gamma, which has been detected within these lesions $(2,3)$, and other lymphokines secreted by $\mathrm{T}$ lymphocytes and monocytes probably induced keratinocyte DR expression $(4,5)$. The close proximity of Herpes simplex virus (HSV) ${ }^{1}$-infected keratinocytes and $T$ lymphocytes within the subjacent infiltrate strongly suggested immunologic interactions: $\mathrm{HSV}$-infected DR positive keratinocytes might present antigens to CD4 positive $T$ lymphocytes or act as targets for cytotoxicity mediated by CD4+ or CD8+ $\mathrm{T}$ lymphocytes. We have developed an in vitro model in which the human keratinocyte expressing HLA-DR induced by interferon gamma (and perhaps other lymphokines) can subserve both of these functions.

\section{Methods}

Patients. Normal HSV seropositive patients undergoing split skin grafts for minor surgical procedures were selected as donors of split skin for keratinocyte culture and of autologous blood mononuclear cells.

Keratinocyte cultures. Split skin was transferred into medium containing high concentrations of antibiotics (Dulbecco's MEM, 0.5\% FCS and pencillin, streptomycin, gentamicin, and amphotericin B) and then cut into $0.5-\mathrm{cm}$ squares. The pieces were rinsed successively in PBS 70\% alcohol, and low antibiotic medium (Dulbecco's MEM, $0.5 \%$ FCS and penicillin, streptomycin, gentamicin, and amphotericin B), incubated in $0.01 \%$ trypsin overnight and then diced into $1-\mathrm{mm}$ squares. The fragments were allowed to adhere to T25 tissue culture flasks (Falcon Labware, Oxnard, CA) and growth medium (Eagle's MEM, with $10 \%$ FCS, (Flow Laboratories, McLean, VA) 10-mM Hepes, $10 \mathrm{ng} / \mathrm{ml}$ epidermal growth factor, cholera toxin $10^{-10} \mathrm{M}$ and $0.5 \mu \mathrm{g} / \mathrm{ml}$ hydrocortisone was added (6).

After 4-7 d, outgrowths of epidermal keratinocytes from the explants were noted by phase-contrast microscopy and these slowly became confluent as a monolayer over $2-4$ wk. Medium was changed twice weekly. Explants with obvious fibroblast outgrowths were removed mechanically. To disperse the monolayer into a single cell suspension, it was first washed with $0.2 \%$ EDTA to remove residual fibroblasts and then incubated with $0.25 \%$ trypsin/EDTA at $37^{\circ} \mathrm{C}$. The washed suspension was dispensed into microtiter wells at a cell concentration of $1-2 \times 10^{4}$ per well. Contaminating fibroblasts as detected by immunoperoxidase staining for vimentin with anti-vimentin MAb (DAKOPATTS, Copenhagen, Denmark) were $<2 \%$ in all patients' cultures (7). This low proportion of contaminating fibroblasts was supported by staining for keratins with rabbit polyclonal antisera (DAKOPATTS). 88-92\% of plated cells were keratin positive, 5-8\% were large keratin-negative cells, probably basal cells, and $2-4 \%$ were small keratin-negative cells, probably mostly fibroblasts. In microtiter wells, $>95 \%$ of the cells had morphologic features of keratinocytes and in some wells held for $2 \mathrm{wk}$, no fibroblast overgrowths were noted. For

1. Abbreviations used in this paper: HSV, herpes simplex virus; TCID $_{50}, 50 \%$ tissue culture infective dose. 
examination by direct immunofluorescence keratinocyte cultures were grown in slide chambers (Lux; Flow Laboratories).

$M A b$. Anti-Leu 3a (CD4), -Leu 2 (CD8), -Leu 4 (CD3), -Leu 11b (CD16), -Leu 10 (DQ) and anti-HLA-DR were obtained from BectonDickinson \& Co., Immunocytometry Systems, Mountain View, CA. Anti-OKT4, -OKT8, and -OKT3 were obtained from Ortho Diagnostics, Raritan, NJ.

Preparation of mononuclear cells and lymphocyte subsets. Mononuclear cells were separated from $40-100 \mathrm{ml}$ of heparinized blood over a Ficoll-Hypaque gradient (Pharmacia Fine Chemicals, Piscataway, NJ). Purified T lymphocytes for the antigen presentation studies were obtained by passage of mononuclear cells over a nylon wool column as previously described (8). The proportion of contaminating monocyte/ macrophages as determined by staining cytocentrifuged smears for nonspecific esterase (9) was $<0.5 \%$. Mononuclear cells were depleted of CD4+ and CD8 + T lymphocytes and Leu 11+ natural killer cells for cytotoxicity studies by complement-dependent cytotoxicity using anti-OKT3, anti-OKT4, anti-OKT8 (Ortho Diagnostics), anti-Leu M3, and anti-Leu $11 \mathrm{lb}$ (Becton-Dickinson \& Co.) MAb as previously described. (8). Briefly, $10^{7}$ mononuclear cells were incubated with 0.1 $\mu \mathrm{g}$ of $\mathrm{MAb}$ at $0^{\circ} \mathrm{C}$ for $30 \mathrm{~min}$, resuspended, washed, and reincubated with prediluted baby rabbit complement (Pel-Freez) for $45 \mathrm{~min}$. The extent of cytotoxicity was assessed by staining with 1:10 trypan blue and counting in a hemocytometer. The viable cell population was recovered after three washes. Residual contaminating cells were $<1 \%$ as determined by flow cytometry using an MAb directed against a different epitope of the same subset marker (e.g. anti-Leu 3a for cytotoxicity with anti-OKT4) or goat anti-mouse IgG to detect residual antibody on unkilled cells and flow cytometry.

Subset deletion was chosen as the method of choice for assessing the function of a subset, thus avoiding functional inhibition by antibody adherent to CD4 or CD8 proteins $(10,11)$.

Virus and antigen. The F strain or a freshly isolated wild strain of Herpes simplex type 1 were used for infection of keratinocytes (12) and preparation of heat inactivated antigen from infected cell lysates as previously described (8). Briefly, antigen was prepared by heating supernatants of freeze-thawed and sonicated HSV-infected Hep2 cells $\left(10^{6} 50 \%\right.$ tissue culture infective dose $\left.\left(\mathrm{TCID}_{50}\right) / \mathrm{ml}\right)$ to $56^{\circ} \mathrm{C}$ for $30 \mathrm{~min}$. Control antigen was prepared by omitting HSV.

Lymphokine preparations. Recombinant IFN gamma (specific activity $=2 \times 10^{7} \mathrm{U} / \mathrm{mg}$ protein; Genentech, South San Francisco, CA), purified IFN gamma (specific activity $=10^{6} \mathrm{U} / \mathrm{mg}$; Cellular Products, Buffalo, NY), and supernatants from PHA-stimulated mononuclear cells (PHA supernatants) were used to stimulate keratinocytes. IFN gamma concentrations in all preparations were assayed and standardized by a dual MAb RIA (Centocor, Malvern, PA) (13).

Measurement of Herpes simplex antigen specific T lymphocyte activation. Herpes simplex antigen was added to mixed keratinocyte-T lymphocyte cultures (ratio $1: 15$ or $1: 30$ ) in microtiter wells at the optimum dilution (11). After $4 \mathrm{~d}$ incubation at $37^{\circ} \mathrm{C}, 1 \mu \mathrm{Ci} /$ well $\left[{ }^{3} \mathrm{H}\right]-$ thymidine was added and the cells harvested $18 \mathrm{~h}$ later with a cell harvester (Titertek; Flow Laboratories, McLean, VA). Incorporated radioactivity was read in a liquid scintillation counter (LKB Instruments, Gaithersburg, MD). HSV-specific T lymphocyte activation was calculated as: stimulation index $=\mathrm{HSV}$-specific $\mathrm{T}$ lymphocyte activation (cpm/well)/nonspecific $\mathrm{T}$ lymphocyte activation (cpm/well).

Assay of cytotoxicity against keratinocyte targets (modified from $14,15)$. Keratinocytes were inoculated with Herpes simplex virus $\left(10^{5}\right.$ TCID $_{50} /$ microtiter well) for $1 \mathrm{~h}$, washed twice with RPMI 1640 medium containing $10 \% \mathrm{FCS}$, incubated with ${ }^{51} \mathrm{Cr}(10 \mu \mathrm{Ci} /$ well $)$ for 90 min, and washed four times with RPMI $1640 / 10 \%$ FCS. Effector mononuclear cells, stimulated with control or Herpes simplex antigen for $6 \mathrm{~d}$ in RPMI 1640/20\% human serum (seronegative for HSV), were added at effector target ratios ranging from 20:1 to 80:1 and incubated for $18 \mathrm{~h}$. Supernatant radioactivity was detected in a gamma counter (model 1185; G. D. Searle \& Co., Skokie, IL) and \% cytotoxicity calculated as: $\%$ specific ${ }^{51} \mathrm{Cr}$ release $=$ test ${ }^{51} \mathrm{Cr}$ release - spontaneous ${ }^{51} \mathrm{Cr}$ release/total ${ }^{51} \mathrm{Cr}$ release - spontaneous ${ }^{51} \mathrm{Cr}$ release.
Preliminary cytotoxicity assays. In preliminary cytotoxicity experiments the following observations were made. (a) Increased washing of keratinocytes was required to reduce the initially high levels of spontaneous release of ${ }^{51} \mathrm{Cr}$. (b) Keratinocytes were often resistant to detergent lysis and also needed freeze-thawing to liberate total ${ }^{51} \mathrm{Cr}$. (c) IFN gamma preparations reduced ${ }^{51} \mathrm{Cr}$ uptake and release (similar to its effect on $\left[{ }^{3} \mathrm{H}\right]$ thymidine), hence reducing both spontaneous and total ${ }^{51} \mathrm{Cr}$ release variably by $23-70 \%$ according to the experiment. $(d)$ The effects of PHA supernatants and purified IFN gamma on ${ }^{51} \mathrm{Cr}$ uptake and on cytotoxicity were similar (see Table II). (e) Effector-target ratios of 80:1 were much superior to 20:1 (Table II). Preliminary experiments comparing ratios of 100:1 and 50:1 to 80:1 demonstrated the peak in percentage specific ${ }^{51} \mathrm{Cr}$ release was achieved at the $80: 1$ ratio and no further increase occurred at 100:1. This ratio was used throughout these experiments to minimize use of donor PBMC.

Statistics. Differences between the sets of results (expressed as mean counts per minute/well of released ${ }^{51} \mathrm{Cr}$ ) which were obtained with different treatments were assessed for statistical significance by $t$ test, with modifications of the degrees of freedom to allow for unequal variances.

\section{Results}

Lymphokine induction of HLA-DR expression by keratinocytes. Human keratinocytes $\left(2 \times 10^{5} /\right.$ cluster well) were incubated with recombinant IFN gamma, purified IFN gamma, and PHA supernatants at concentrations of 20 to $100 \mathrm{U} / \mathrm{ml}$ for $4 \mathrm{~d}$. The cells were detached with $0.25 \%$ trypsin/0.2\% EDTA and stained with anti-HLA-DR and -DQ (anti-Leu 10) MAb and examined by flow cytometry (10,000 cells counted). All preparations induced $85-90 \%$ of keratinocytes to express HLA-DR but not -DQ at optimal concentrations of 50-100 $\mathrm{U} / \mathrm{ml}$, (Fig. 1), consistent with previously reported results (4, 5). No Leu 6+, HLA DR+ Langerhans cells, or HLA DR+ dermal dendritic cells were detected in parallel control keratinocyte cultures.

Herpes simplex antigen presentation by IFN gamma-stimulated keratinocytes to nylon wool purified $T$ lymphocytes. $1 / 10$ dilutions of HSV antigen (previously determined to be optimal for antigen presentation) were added to keratinocytes $\left(1-2 \times 10^{4} /\right.$ well) stimulated with either recombinant or purified IFN gamma or PHA supernatants $(100 \mathrm{U} / \mathrm{ml})$ for $4 \mathrm{~d}$ and mixed with nylon wool-purified lymphocytes $\left(3 \times 10^{5} /\right.$ well). T lymphocyte activation was determined by $\left[{ }^{3} \mathrm{H}\right]$ thymidine incorporation. Preliminary experiments showed that addition of $\left[{ }^{3} \mathrm{H}\right]$ thymidine for $18 \mathrm{~h}$ at day four produced higher incor-

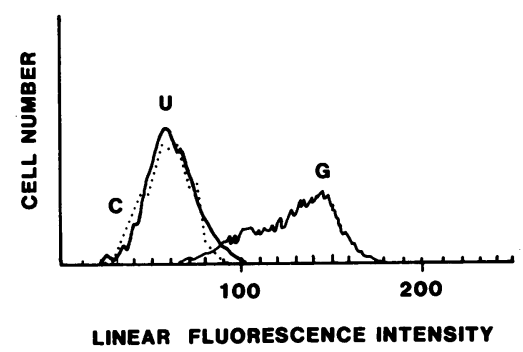

Figure 1. HLA-DR expression by human epidermal keratinocytes before and after stimulation with IFN gamma. Human keratinocytes (2 $\times 10^{5} /$ cluster well were stimulated with 100 $\mathrm{U} / \mathrm{ml}$ recombinant IFN gamma for $4 \mathrm{~d}$, detached with trypsin-versene, stained with fluorescein-conjugated anti-HLA-DR or control MAb (anti-Leu 2b) and examined by flow cytometry. Mock-stimulated keratinocytes were also stained with anti-HLA-DR MAb. U, unstimulated + anti HLA-DR MAb; C, IFN gamma + control MAb; and G, IFN gamma + anti HLA-DR MAb. Note the high degree of autofluorescence of keratinocytes not expressing HLA-DR. 
poration than addition at days 3 or 5 (e.g. day $3,3,654 \pm 178$; day 4, 4,538 \pm 240 ; day 5: 4,050 \pm 289 ; mean \pm 1 SD cpm). Controls for nonspecific lymphocyte activation were obtained by using similar cultures but omitting IFN gamma, HSV antigen, IFN gamma and keratinocytes, or incubating NWP lymphocytes alone. All test and control experiments were performed in triplicate.

As shown in Table $I$, the significant increase in $\left[{ }^{3} \mathrm{H}\right]-$ thymidine incorporation by NWP cells after HSV antigen stimulation in patient 1 suggested contamination with a small proportion of antigen-presenting cells. Similarly, in the two cultures tested, IFN gamma-stimulated (and HLA-DR expressing) keratinocytes induced a small but significant increase in T lymphocyte activation, in the absence of HSV antigen. Addition of HSV antigen to the latter cultures produced a marked and significant increase in $T$ lymphocyte response in all four cultures $(P<0.02, t=4.59-14.15$; stimulation indices 1.5-2.7; Table I). Nevertheless, this maximum response was less than observed in HSV antigen-stimulated PBMC or macrophage-T lymphocyte cultures (10). Recombinant IFN gamma-stimulated keratinocytes did not induce $\mathrm{T}$ lymphocyte activation with or without HSV antigen (patients 3 and 4). Incubation of neutralizing MAb to IFN gamma (B3; kindly supplied by Dr. J. Vilcek; reference 15) with PHA supernatants for $1 \mathrm{~h}$ before addition of the mixture blocked the $\mathrm{T}$ lymphocyte response to keratinocytes without $\mathrm{HSV}$ antigen and also partially blocked the antigen-induced response (patient 4).

Cytotoxicity of HSV antigen-stimulated mononuclear cells for keratinocytes with and without IFN gamma stimulation. In preliminary experiments $\mathrm{HSV}$ at $10^{5} \mathrm{TCID}_{50} / \mathrm{ml}$ was added to keratinocytes with and without prior stimulation with PHA supernatants (100 U/ml of IFN gamma) in slide chambers. The cells were fixed with acetone at 8,18 , and $24 \mathrm{~h}$ and stained with fluorescein-conjugated MAb to HSV glycoprotein C. By 8 $\mathrm{h}$, intense cytoplasmic fluorescence was observed in most unstimulated keratinocytes. At this time, occasional stimulated keratinocytes showed focal cytoplasmic fluorescence but equivalent diffuse cytoplasmic fluorescence was only observed at $18 \mathrm{~h}$. Cytopathic effect was obvious in unstimulated kera- tinocytes at $18 \mathrm{~h}$ but was less marked in stimulated keratinocytes (reference 11). Similarly, ${ }^{51} \mathrm{Cr}$ release from HSV-infected keratinocytes was not significantly raised above spontaneous release levels in four cytotoxicity experiments.

Table II shows the HSV-specific and control cytotoxicity assays for eight subjects. There was a wide variation in ${ }^{51} \mathrm{Cr}$ uptake and hence total and spontaneous release. Mononuclear cells that had not been activated with HSV antigen showed no significant cytotoxicity (in comparison with spontaneous release). However, in four of eight of the subjects (patients 2, 5, 6,7 and also patient 2 [Table III], where target keratinocytes were not infected) small but significant increases in cytotoxicity against uninfected but IFN gamma-stimulated target keratinocytes was observed. (An even smaller degree of cytotoxicity, $15 \%$ specific ${ }^{51} \mathrm{Cr}$ release, was seen in one of three experiments with uninfected, unstimulated keratinocytes.) The cell types involved in this autoreactive cytotoxicity are analyzed in Table III. Both T lymphocytes and Leu $11 \mathrm{~b}+$ natural killer cells were active, with the former predominating. $T$ lymphocyte cytotoxicity against these IFN-stimulated HLA-class I and II antigen-expressing cells was reduced approximately equally by deletion of CD4+ and CD8+ lymphocyte subsets.

Mononuclear cell cytotoxicity specific for HSV-infected keratinocytes was augmented by IFN gamma stimulation of the keratinocytes (Table II) as shown by comparison of percent specific ${ }^{51} \mathrm{Cr}$ release with and without IFN gamma stimulation of keratinocytes in patients 1,2 , and 5 i.e., 83 vs. $56 \%, 86$ vs. $51 \%$, and 82 vs. $17 \%$, respectively. In patient 1 , there was no autoreactive cytotoxicity and still a difference of $27 \%$. However, the large difference in patient 5 may have been partly due to extensive autoreactive cytotoxicity contributing to apparent HSV-specific class II restricted cytotoxicity (compare also in Tables III and IV). Mononuclear cell cytotoxicity for HSV-infected, IFN gamma-stimulated keratinocytes was significantly greater than that for uninfected target keratinocytes in all nine experiments (eight patients) shown in Table II and ranged from 43 to $86 \%$ of specific ${ }^{51} \mathrm{Cr}$ release. Attempts were made to determine the lymphocyte types mediating the cytotoxicity initially by panning i.e., by adherence of specific lymphocyte subsets to a subset-specific MAb adherent to a solid phase (8).

Table I. Herpes Simplex Antigen Specific T Lymphocyte Activation by IFN Gamma-stimulated Keratinocytes

\begin{tabular}{|c|c|c|c|c|c|c|}
\hline \multirow[b]{2}{*}{$\begin{array}{l}\text { Patient } \\
\text { no. }\end{array}$} & \multicolumn{6}{|c|}{$\left[{ }^{3} \mathrm{H}\right]$ Thymidine incorporation } \\
\hline & $\begin{array}{l}\text { T lymphocytes } \\
\text { alone }\end{array}$ & $\begin{array}{l}\text { Herpes antigen } \\
+T \text { lymphocytes }\end{array}$ & $\begin{array}{l}\text { Keratinocytes } \\
+ \text { T lymphocytes }\end{array}$ & $\begin{array}{c}\text { IFN } \gamma \text {-stimulated* keratinocytes } \\
+ \text { T lymphocytes }{ }^{\ddagger}\end{array}$ & $\begin{array}{l}\text { Herpes antigen } \\
+ \text { keratinocytes } \\
+\mathrm{T} \text { lymphocytes }\end{array}$ & $\begin{array}{c}\text { Herpes antigen + IFN } \gamma \text {-stimulated } \\
\text { keratinocytes }+\mathrm{T} \text { lymphocytes }^{\ddagger}\end{array}$ \\
\hline & & & & mean cpm/microtiter well $\pm 1 S D$ & & \\
\hline 1 & $772 \pm 232$ & $2,442 \pm 353$ & ND & $2,283 \pm 238$ & $2,750 \pm 289$ & $6,109 \pm 948$ \\
\hline 2 & $1,147 \pm 215$ & $1,921 \pm 353$ & ND & $1,858 \pm 242$ & $2,192 \pm 266$ & $\begin{array}{l}4,552 \pm 1,041 \\
(2,006 \pm 248)^{\S}\end{array}$ \\
\hline 3 & $2,266 \pm 590$ & ND & $2,393 \pm 157$ & $3,190 \pm 112$ & $\begin{array}{c}2,998 \pm 221 \\
(3,057 \pm 276)^{\S}\end{array}$ & $\begin{array}{l}4,781 \pm 195 \\
(3,760 \pm 515)^{\S}\end{array}$ \\
\hline 4 & $1,668 \pm 307$ & ND & $1,281 \pm 321$ & $\begin{array}{c}2,582 \pm 226^{\prime \prime} \\
(1,050 \pm 104)\end{array}$ & $1,410 \pm 337$ & $\begin{array}{l}5,616 \pm 1,030^{\prime \prime} \\
(1,025 \pm 282)^{\S}\end{array}$ \\
\hline
\end{tabular}

\footnotetext{
* IFN $\mathrm{I}_{\gamma}=$ supernatants from PHA-stimulated mononuclear cells. $\quad$ ₹ Stimulation index $=$ HSV-specific $\mathrm{T}$ lymphocyte activation/non-specific $\mathrm{T}$ lymphocyte activation $=2.7,2.3,1.5$, and 2.2 for patients $1,2,3$, and 4 , respectively. $t=7.56,5.42,14.15$, and 5.75 for patients $1,2,3$, and 4 , respectively; $P<0.01,0.02,0.001,0.01$. \$Stimulated with recombinant IFN gamma. "After blocking PHA supernatant stimulation of keratinocytes with B3 anti-IFN gamma MAb: $2,582 \pm 226 \rightarrow 1,092 \pm 141 ; 5,616 \pm 1,030 \rightarrow 3,354 \pm 178$.
} 
Table II. Cytotoxicity of HSV Antigen-stimulated Mononuclear Cells for IFN Gamma-stimulated and HSV-infected Keratinocytes

\begin{tabular}{|c|c|c|c|c|c|}
\hline \multirow[b]{2}{*}{ Patient } & \multirow[b]{2}{*}{ Lymphokine preparation } & \multicolumn{2}{|c|}{ Controls } & \multicolumn{2}{|c|}{ Test } \\
\hline & & No HSV antigen stimulation & No HSV infection (of keratinocytes) & 20:1 & $80: 1$ \\
\hline & & \multicolumn{4}{|c|}{ Mean percentage specific ${ }^{51} \mathrm{Cr}$ release $( \pm I S D)$} \\
\hline \multirow[t]{3}{*}{1} & PHA S/N & $4.3 \pm 5.8$ & $13.4 \pm 4.7$ & $14.5 \pm 2.2$ & $83.5 \pm 4.1^{*}$ \\
\hline & (No PHA S/N) & & & & $(56.0 \pm 20.2)$ \\
\hline & pIFN- $\gamma$ & ND & $6.8 \pm 8.7$ & $5.5 \pm 2.2$ & $64.4 \pm 3.2^{*}$ \\
\hline \multirow[t]{2}{*}{2} & PHA S/N & $15.1 \pm 1.3$ & $28.7 \pm 7.1$ & & $85.6 \pm 18.0^{*}$ \\
\hline & (No PHA S/N) & & & & $(50.7 \pm 4.1)$ \\
\hline 3 & PHA S/N & $7.9 \pm 4.4$ & $11.4 \pm 7.9$ & & $42.7 \pm 10.5^{*}$ \\
\hline 4 & PHA S/N & $-12.4 \pm 7.8$ & $9.9 \pm 13.0$ & & $46.0 \pm 12.8^{*}$ \\
\hline \multirow[t]{2}{*}{5} & PHA S/N & $10.1 \pm 4.2$ & $72.2 \pm 6.0$ & & $82.0 \pm 2.1^{\ddagger}$ \\
\hline & (No PHA S/N) & & & & $(16.5 \pm 2.8)$ \\
\hline 6 & PHA S/N & ND & $32.4 \pm 1.7$ & & $71.6 \pm 8.2^{*}$ \\
\hline 7 & pIFN $\gamma$ & $24.0 \pm 5.7$ & $56.5 \pm 4.9$ & & $82.1 \pm 2.5^{*}$ \\
\hline 8 & IFN S/N & $-2.3 \pm 2.0$ & $-1.2 \pm 3.3$ & & $51.1 \pm 3.8^{*}$ \\
\hline
\end{tabular}

All cytotoxicity assays shown used an E/T ratio of 80:1. Spontaneous release values fell within the range of 20 to $30 \%$ of total releasable counts of ${ }^{51} \mathrm{Cr}$. ${ }^{*} P<0.001,{ }^{\ddagger} P<0.05$ by $t$ test for differences in mean counts per minute/well of released ${ }^{51} \mathrm{Cr}$ between infected and uninfected keratinocytes.

Poor separation was achieved with the mononuclear cells that had been stimulated with HSV antigen for $6 \mathrm{~d}$. However, subset deletion using anti-OKT3,-OKT4, -OKT8, and -Leu 11b and complement was satisfactory, with $<1 \%$ residual contaminating cells as determined by flow cytometry. Treatment with complement alone in two patients did not significantly reduce mononuclear cell cytotoxicity (data not shown). As shown in Table IV, both $T$ lymphocytes and Leu $11 \mathrm{~b}$ natural killer cells mediated the cytotoxicity. In six of seven experiments focusing on the $\mathrm{T}$ lymphocyte cytotoxicity, there was no significant difference between CD4+ and CD8+ lymphocyte-mediated killing, but in one experiment (patient 1) CD4+ T lymphocyte killing predominated.

\section{Discussion}

In this in vitro model of a human recurrent herpes simplex lesion, IFN gamma or mixed lymphokine-stimulated, HLADR expressing human keratinocytes were capable of both presenting herpes simplex antigen to $T$ lymphocytes and act-

Table III. Mononuclear Cell Cytotoxicity for Uninfected IFN Gamma-stimulated Keratinocytes: Results of Lymphocyte Subset Deletion

\begin{tabular}{ccccccc}
\hline Patient & Untreated & - CD3 & - CD4 & - CD8 & -Leu 11b & -Leu M5 \\
\hline \multicolumn{7}{c}{ Mean percentage specific ${ }^{51}$ Cr release $( \pm 1$ SD) } \\
1 & $72.2 \pm 6.0$ & $27.4 \pm 5.6$ & $57.6 \pm 2.5$ & $53.2 \pm 3.7$ & $56.9 \pm 6.3$ \\
2 & $37.7 \pm 14.9^{*}$ & $9.0 \pm 4.4$ & ND & ND & $19.7 \pm 2.6^{*}$ & $33.8 \pm 16.5^{*}$ \\
3 & $32.4 \pm 1.7^{\ddagger}$ & $8.9 \pm 4.3$ & $24.5 \pm 8.0^{\ddagger}$ & $23.5 \pm 4.8$ & ND & \\
& & & & & \\
\hline
\end{tabular}

All cytotoxicity assays shown used an E/T ratio of 80:1. Ratios of 20:1 showed no significant percent specific ${ }^{51} \mathrm{Cr}$ release. Spontaneous release values fell within the range of 20 to $30 \%$ of total releasable counts of ${ }^{51} \mathrm{Cr}$.

* Differences not significant by $t$ test. ing as targets for HSV-specific T lymphocyte cytotoxicity. Lymphocyte subset analysis also showed that CD4+ lymphocytes were capable of cytotoxicity against these HSV-infected DR+ keratinocytes.

It is now well established that IFN gamma can induce HLA-class II antigen expression de novo by a wide variety of cell types (17). However, these cells vary in their ability to present antigen, even when class II antigen expression is equivalent (18). In the experiments described here, the antigenpresenting capacity of the DR+ keratinocytes was relatively weak compared with macrophages or monocytes $(8,11)$, even in the presence of IL 1 (data not shown). This requires further investigation, but qualitative differences linked with the lack of expression of DQ or quantitative differences such as a relatively lower density of membrane DR expression or the absence of an important costimulatory signal may all be important. In this respect, the relatively poor induction of antigenpresenting capacity by recombinant IFN gamma compared with PHA supernatants or partially purified IFN gamma (Table I) seems paradoxical as all were standardized for IFN gamma content and were approximately equal in inducing HLA-DR expression. This also requires further study but may be explained by lower stability of the recombinant preparation or the presence of other important HLA class II antigen-stimulating lymphokines, such as tumor necrosis factor, in the less purified preparations (19). In the keratinocyte-autologous $T$ lymphocyte system described here it is important to maintain fibroblast contamination at a very low level, as IFN gammacontaining preparations can also induce HLA-DR expression on these cells, although their antigen-presenting capacity is very weak (18). The importance of Ia + , Leu $6+$ Langerhan's cells as antigen presenting cells in skin has been well established $(15,20)$ but these cells were not detected in this system. However, it seems likely that in vivo HSV-infected keratinocytes would provide only accessory HSV antigen presentation to that provided by Langerhan's cells and dermal dendritic 
Table IV. Mononuclear Cell Cytotoxicity Specific for HSV-infected, IFN Gamma-stimulated Keratinocytes Results of Lymphocyte Subset Deletion (by MAb and Complement)

\begin{tabular}{ccccccc}
\hline Patient & Lymphokine preparation & Untreated & -CD3 & -CD4 & -CD8 \\
\hline & & & \multicolumn{3}{c}{ Mean percentage specific ${ }^{51}$ Cr release $( \pm S D)$} \\
1a & PHA S/N & $54.7 \pm 9.1^{*}$ & ND & $36.0 \pm 7.1$ & $47.2 \pm 3.7^{*}$ & $49.6 \pm 2.9^{*}$ \\
b & Purified IFN $\gamma$ & $85.2 \pm 17.1$ & ND & $54.4 \pm 6.8$ & $50.9 \pm 8.0$ & $45.1 \pm 3.8$ \\
$2 \mathrm{a}$ & PHA S/N & $55.8 \pm 1.8^{\ddagger}$ & $22.3 \pm 2.5$ & $28.7 \pm 5.31$ & $38.6 \pm 20.7^{\ddagger}$ & ND \\
b & Purified IFN $\gamma$ & $59.2 \pm 2.2$ & $35.2 \pm 3.0$ & $40.3 \pm 2.5$ & $46.2 \pm 4.1$ & ND \\
3 & PHA S/N & $82.0 \pm 2.1^{\S}$ & $27.4 \pm 5.6$ & $57.6 \pm 2.5$ & $53.2 \pm 3.7$ & $56.9 \pm 6.3$ \\
4 & PHA S/N & $71.6 \pm 8.3$ & $40.1 \pm 4.2$ & $43.8 \pm 4.9$ & $39.0 \pm 7.4$ & ND \\
5 & Purified IFN $\gamma$ & $82.1 \pm 2.5$ & $50.1 \pm 7.9$ & $51.2 \pm 2.0$ & $53.3 \pm 8.4$ & ND \\
\hline
\end{tabular}

All cytotoxicity assays shown used an E/T ratio of 80:1. Ratios of 20:1 showed no significant percent specific ${ }^{51} \mathrm{Cr}$ release. Spontaneous release values fell within the range of 20 to $30 \%$ of total releasable counts of ${ }^{51} \mathrm{Cr}$. ${ }^{* \ddagger}$ Differences not significant by $t$ test. ${ }^{\S}$ Represents HSV-specific and nonspecific killing.

cells, present in skin at the commencement of HSV reinfection, and infiltrating activated macrophages, capable of digesting whole virus into small peptides. The latter cells have the advantage of constitutive HLA class II antigen expression, whereas induction of these antigens on keratinocytes by lymphokines secreted by activated $T$ lymphocytes requires $1-2 \mathrm{~d}$ $(2,4)$.

HSV antigen-primed mononuclear cell cytotoxicity for HSV-infected keratinocytes was greater when these cells were stimulated with IFN gamma and expressed HLA-DR in vitro, suggesting that augmentation of class I restricted cytotoxicity and recruitment of class II restricted CD4+ lymphocyte-mediated cytotoxicity by this mechanism are important in vivo. The in vitro results were similar whether partially purified IFN gamma or PHA supernatants were used for stimulation.

The variable mononuclear cell cytotoxicity for uninfected IFN gamma-stimulated keratinocytes, mediated by CD4+ and CD8 + $\mathrm{T}$ lymphocytes and Leu $11+$ natural killer cells, partially obscured HSV specific cytotoxicity to different degrees in $50 \%$ of the patients. Similar autoreactivity was noted in the antigen presentation experiments. In both cases it was more prominent when keratinocytes were stimulated with IFN gamma, inducing HLA class II antigen expression and increasing the intensity of HLA class I expression. Similar results have also been reported in which CD4+ lymphocyte mediated cytotoxicity was found to be specific for components of FCS present in the culture medium and taken up by target cells (21). In our experiments, human serum was used in culture medium for HSV antigen priming of $\mathrm{T}$ lymphocytes and the keratinocytes were cultured in FCS. Possibly the cytotoxic T cells may have recognized antigenic epitopes common to both sera or other endogenous or exogenous antigens expressed on the surface of keratinocytes in association with HLA-DR. The variability observed may relate to differences in the concentrations of residual antigens, to differential affinity of serum antigens for different HLA-DR phenotypes or to augmented induction of autoreactivity by certain phenotypes. Recently Tilkin et al. have demonstrated that in vitro stimulation with (influenza) viral antigens induced both virus-specific and autoreactive $T$ cell clones (22). The small number of autoreactive clones were specific for HLA-DR antigens and were capable of both proliferative and cytotoxic activity, very similar to the results obtained here. Recent crystallographic studies of HLA class I antigens have also shown that peptide antigens, probably derived from the medium or the cell itself, are always bound to the HLA molecule providing appropriate autoreactive stimuli or targets (23). Culture of keratinocytes in defined serum-free medium should determine whether serum antigens are important (24). If the cytotoxicity was directed against residual endogenous or exogenous antigens it raises the question of whether autoreactive cytotoxic $T$ cells directed against antigens associated with newly induced HLA class II or denser class I antigens might restrict the spread of HSV infection by killing adjacent keratinocytes before membrane expression of HSV antigens. By analogy, epidermal damage, manifested by lichenoid tissue reaction, has been induced by injection of murine self Ia-specific autoreactive cytotoxic $\mathrm{T}$ cells into the footpads of mice (25). Presumably natural killer cells activated by HSV glycoproteins or by IFN and IL 2 within the primed cultures in vitro showed some slight reactivity towards cell membrane antigens altered by interferon gamma stimulation (26-28).

The importance of CD8+ lymphocyte-mediated, HLA class I antigen-restricted cytotoxicity, natural killer cell activity, and macrophage activation in immunity against primary HSV infection has been well established in animal models (29-31). Although CD4+ lymphocyte-mediated class II-restricted cytotoxicity has also been well demonstrated in vitro against influenza and by clonal studies against HSV and measles (32-34), there is skepticism about the importance of their role in vivo (35). Further evidence for its importance in herpesvirus infections has been demonstrated recently with EBV and HSV infection $(36,37)$. In the latter study of HSV1 seropositive patients blood cytotoxic precursor frequency to HSV-infected, EBV-transformed B cells was determined. CD4+ lymphocyte mediated, class II-restricted cytotoxicity and natural killer cell activity predominated, similar to the results reported here with keratinocyte targets. The experiments in Table I show clear evidence of approximately equal CD4+ and CD8+ T lymphocyte cytotoxicity and natural killer cell activity specific for HSV-infected, IFN gamma-stimulated keratinocytes. These results are predictable from current models of cytotoxicity. IFN gamma not only induces membrane expression of HLA class II antigens in many cell 
types but also increases class I antigen density (4, 5). CD8+ cytotoxic $\mathrm{T}$ lymphocytes recognize alloantigens in association with HLA class I antigens and CD4+ cytotoxic T lymphocytes usually in association with HLA class II $(34,37)$. The mode of induction of CD4+ cytotoxic $\mathrm{T}$ lymphocytes by HSV antigen presentation by monocytes macrophages and dendritic cells in vitro probably also occurs in vivo as macrophages make up $10-15 \%$ of mononuclear infiltrate cells in herpetic lesions and Langerhans cells and probably dermal dendritic cells are present (2). The generation of lymphokines within the HSV antigen-primed mononuclear cultures or direct stimulation by HSV glycoproteins would be expected to activate natural killer cells, which have been previously shown to kill HSV-infected fibroblasts (26-28).

Although this keratinocyte-autologous $\mathrm{T}$ lymphocyte model has been most useful in confirming the suggested immunologic role of the HLA-DR+ keratinocyte in recurrent herpetic lesions, it needs to be refined, particularly if it is to be used in evaluating structural and nonstructural proteins that are targets for HSV-specific cytotoxicity in the lesions (39). The most important of these is the limitation on numbers of keratinocytes and autologous $\mathrm{T}$ lymphocytes that can be easily obtained, thus restricting the scope of comparative experiments in the one patient. It is possible that HSV antigen priming of mononuclear cells (using HLA-DR and -DQ expressing monocytes/dendritic cells for antigen presentation) may lead to differences in antigenic epitope recognition on HLA-DR+ keratinocytes, although this probably occurs in the lesion. Increasing the supply of keratinocytes, perhaps by transformation with SV40-Adenovirus 12 recombinant virus (40), would allow comparisons of keratinocytes and monocytes as antigen-presenting cells in the priming reaction. The immunologic and biologic changes induced by transformation would have to be carefully compared with control keratinocytes. The natural killer cell activity demonstrated here is unlikely to be a prominent feature in vivo as the cells are underrepresented in recurrent herpetic lesions compared with peripheral blood (2). Interference with HSV specific cytotoxicity by autoreactive cytotoxicity, marked in one of eight patients, limits the reproducibility and clarity of the assay for assessment of important HSV target peptides in this model. Cloning of HSVspecific CD4+ and CD8+ cytotoxic $T$ cells or estimating the specific cytotoxic precursor frequency to the various peptides may eliminate this problem, $(39,41)$ avoid irrelevant natural killer cell activity, and determine the target peptides for class Ior class II-restricted cytotoxicity. In view of the predominance of CD4+ T lymphocytes in lesions at the time when HSV titers in vesicle fluid start to fall $(2,42)$, they may be the most important cytotoxic cell involved in limiting local spread of HSV infection and subsequent eradication of epidermal infection. This hypothesis is consistent with the marked persistence of anal recurrent herpetic lesions in patients with AIDS (43).

\section{Acknowledgments}

We thank Dr. C. Thomson and Ms. B. Rose for assistance with keratinocyte cultures, Ms. J. Millikan for performing histochemical stains, and Ms. W. Timeus for typing the manuscript.

This work was supported by a project grant from the National Health and Medical Research Council of Australia.

\section{References}

1. Roizman, B., and C. Lopez, editors. 1985. The Herpesviruses. Vol. 4. Immunobiology and Prophylaxis of Human Herpesvirus Infections. Plenum Publishing Corp. New York/London. 1-430.

2. Cunningham, A. L., R. R. Turner, A. C. Miller, M. F. Para, and T. C. Merigan. 1985. Evolution of recurrent herpes simplex lesions: an immunohistologic study. J. Clin. Invest. 75:226-233.

3. Torseth J. W., B. J. Nickoloff, T. Y. Basham, and T. C. Merigan. 1987. Interferon produced by keratinocytes in human cutaneous infection with herpes simplex virus. J. Infect. Dis. 155:641-648.

4. Basham, T. Y., B. J. Nickoloff, T. C. Merigan, and V. Morhenn. 1985. Recombinant gamma interferon differentially regulates Class II antigen expression and biosynthesis on cultured normal human keratinocytes. J. Interferon Res. 5:23-32.

5. Aubock J., R. N. Niederwieser, P. Fritsch, and C. Huber. 1985. Human interferon induces expression of HLA-DR on keratinocytes and melanocytes. Arch. Dermatol. Res. 277:270-275.

6. Thompson, C., B. Rose, A. Fletcher, C. Harbour, and Y. Cossart. 1986. Expression of blood group antigens by cultured human epidermal cells. J. Invest. Dermatol. 86:394-398.

7. Kariniemi, A. L., V. P. Lehto, T. Vartio, and I. Virtanen. 1982. Cytoskeleton and pericellular matrix organisation of pure adult human keratinocytes cultured from suction-blister roof epidermis. J. Cell Sci. $58: 49-61$.

8. Cunningham, A. L., and T. C. Merigan. 1984. Leu3 positive produce gamma interferon in patients with recurrent herpes labialis. $J$. Immunol. 132:197-202.

9. Yam, L. T., C. Y. Li, and W. H. Crosby. 1971. Cytochemical identification of monocytes and granulocytes. Am. J. Clin. Pathol. 55:282-290.

10. Engleman, E. G., C. J. Benike, E. Clickman, and R. L. Evans. 1981. Antibodies to membrane structures that distinguish cytotoxic/ suppressor and helper $\mathrm{T}$ lymphocyte subpopulations block the mixed leukocyte reaction in man. J. Exp. Med. 154:193-202.

11. Cunningham, A. L., T. Y. Basham, M. F. Para, and T. C. Merigan. 1985. Role of macrophage D-region antigens and T-lymphocyte differentiation antigens in induction of gamma interferon. $J$. Interferon Res. 5:477-491.

12. Schnipper, L. E., M. Levin, C. S. Crumpacker, and B. A. Gilchrest. 1984. Virus replication and induction of interferon in human epidermal keratinocytes following infection with herpes simplex virus. J. Invest. Dermatol. 82:94-96.

13. Le, J., B. S. Barrowclough, J. Vilcek. 1984. Monoclonal antibodies to human immune interferon and their application for affinity chromatography. J. Immunol. Methods. 69:61-70.

14. Faure, M., C. Dezutter-Dambuyant, D. Schmitt, M. Gaucherand, and J. Thivolet. 1985. Human epidermal cell-induced generation of alloreactive cytotoxic T-lymphocytes responses against epidermal cells. Scand. J. Immunol. 21:441-446.

15. Steiner, G., K. Wolfe, M. Pehamberger, and L. G. Sting. 1985. Epidermal cells as accessory cells in the generation of allo-reactive and hapten-specific cytotoxic T lymphocyte (CTL) responses. J. Immunol. 134:736-741.

16. Chang, T. W., S. McKinney, V. Liu, P. C. King, J. Vilcek, and J. Le. 1984. Use of monoclonal antibodies as sensitive and specific probes for biologically active gamma-interferons. Proc. Natl. Acad. Sci. USA. 81:5219-5222.

17. Rosa, F., and M. Fellous. 1984. The effect of gamma-interferon on MHC antigens. Immunol. Today. 5:261-262.

18. Geppert, T. D., and P. E. Lipsky. 1985. Antigen presentation by interferon treated endothelial cells and fibroblasts: differential ability to function as antigen-presenting cells despite comparable Ia expression. J. Immunol. 135:3750-3761.

19. Massa, P. T., A. Schimpl, E. Wecker, V. ter Meulen. 1987. Tumor necrosis factor amplifies measles virus mediated in induction on astrocytes. Proc. Natl. Acad. Sci. USA. 84:7242-7245. 
20. Braathen, L. R., E. Berle, U. Mobech-Hanssen, and E. Thorsby. 1980. Studies on human epidermal Langerhans cells. II Activation of human $\mathrm{T}$ lymphocytes to herpes simplex virus. Acta Dermatovenerol. Iugosl. 60:381-387.

21. Misko, I. S., T. D. Soszynski, R. G. Kane, and J. M. Pope. 1984. Factors influencing the human cytotoxic $\mathrm{T}$ cell response to autologous lymphoblastoid cell lines in vitro. Clin. Immunol. Immunopathol. 32:285-297.

22. Tilkin, A. F., J. Michon, D. Juy, M. Kayibanda, Y. Henin, G. Sterkers, M. Bethuel, and J. P. Levy. 1987. Autoreactive T cell clones of MHC class II specificity are produced during responses against foreign antigens in man. J. Immunol. 138:67-679.

23. Bjorkman, P. J., M. A. Saper, B. Samraoui, W. S., J. L. Strominger, and P. C. Wiley. 1987. Structure of the human class I histocompatibility antigen, HLA-A2. Nature (Lond.). 329:506-529.

24. Furukawa, F., J. C. Huff, W. L. Weston, and D. A. Norris. 1987. Serum-free serial culture of adult human keratinocytes from suction-blister roof epidermis. J. Invest. Dermatol. 89:460-463.

25. Shiohara, T., N. Moriya, T. Mochizuki, and M. Nagashima. 1987. Lichenoid tissue reaction (LTR) induced by local transfer of Ia-reactive T-cell clones. II. LTR by epidermal invasion of cytotoxic lymphokine producing autoreactive T cells. J. Invest. Dermatol. 89:8-14.

26. Fitzgerald, P., P. Von Wusow, and C. Lopez. 1982. Role of interferon in the natural kill of HSV-1 infected fibroblasts. J. Immunol. 129:819-823.

27. Colmenares C., and C. J. Lopez. 1986. Enhanced lysis of herpes simplex virus type 1-infected mouse cell lines by NC and NK effectors. J. Immunol. 136:3473-3480.

28. Casali, P., J. G. P. Sissons, M. J. Buchmeier, and M. B. A. Oldstone. 1981. In vitro generation of human cytotoxic lymphocytes by virus. Viral glycoproteins induce nonspecific cell mediated cytotoxicity without release of interferon. J. Exp. Med. 154:840-855.

29. Larsen, H. S., R. G. Russell, and B. T. Rouse. 1983. Recovery from lethal herpes simplex virus type 1 infection is mediated by cytotoxic T lymphocytes. Infect. Immun. 41:197-204.

30. Rager-Zisman, B., P. C. Quan, M. Rosner, J. R. Moller, and B. R. Bloom. 1987. Role of NK cells in protection of mice against herpes simplex virus 1 infection. J. Immunol. 138:884-888.

31. Zisman, B., M. S. Hirsch, and A. C. Allison. 1970. Selective effects of anti-macrophage serum, silica and anti-lymphocyte serum on pathogenesis of herpesvirus infection of young mice. J. Immunol. 104:1155-1159.
32. Morrison, L. A., A. E. Luckacher, V. L. Braciale, D. P. Fan, and V. L. Braciale. 1984. Differences in antigen presentation to MHC class I and class II restricted influenza virus-specific cytolytic T lymphocyte clones. J. Exp. Med. 163:903-921.

33. Yasukawa, M., and J. M. Zarling. 1984. Human cytotoxic T cell directed against herpes simplex virus-infected cells. J. Immunol. 133:422-427.

34. Jacobson, S., J. R. Richert, W. E. Biddison, A. Satinsky, R. J. Hartzman, and M. F. McFarland. 1984. Measles virus specific T4+ human cytotoxic $\mathrm{T}$ cell clones are restricted by class II HLA antigens. J. Immunol. 133:754-757.

35. Braakman, E., T. M. Rotteveel, G. Van Bleek, G. A. van Seventer, and C. J. Lucas. 1987. Are MHC class II-restricted cytotoxic T lymphocytes important? Immunol. Today. 8:265-267.

36. Misko, I. S., J. M. Pope, R. Hutter, T. D. Soszynski, and R. G. Kane. 1984. HLA-DR antigen associated restriction of EBV-specific cytotoxic T-cell colonies. Int. J. Cancer. 33:239-243.

37. Schmid, S. 1988. The human MHC restricted cellular response to herpes simplex type 1 is mediated by CD4+, CD8-T cells and is restricted to the DR region of the MHC complex. J. Immunol. 140:3610-3616.

38. Meuer, S. C., S. F. Schlossman, and E. Reinhertz. 1982. Clonal analysis of human cytotoxic T lymphocytes: T4+ and T8+ effector T cells recognise products of different major histocompatibility complex regions. Proc. Natl. Acad. Sci. USA. 79:4395-4399.

39. Zarling, J. M., P. A. Moran, R. L. Burke, C. Pacha, P. Berman, and L. A. Lasky. 1986. Human cytotoxic T cell clones directed against herpes simplex virus-infected cells. J. Immunol. 136:4669-4673.

40. Rhim, J. S., G. J. Jay, P. Arnstein, F. N. Price, K. K. Sanford, and S. A. Aaronson. 1985. Phenotypic transformation of human epidermal keratinocytes by AD12-SV40 and Kirsten sarcoma viruses. Science (Wash. DC). 227:1250-1252.

41. Reddehase, J., and U. H. Koszinowski. 1984. Significance of herpesvirus immediate early gene expression in cellular immunity to cytomegalovirus infection. Nature (Lond.). 312:369-374.

42. Spruance, S. L., J. C. Overall, E. R. Kern, G. C. Krueger, V. Pliam, and W. Miller. 1977. The natural history of recurrent herpes simplex labialis. N. Engl. J. Med. 279:69-75.

43. Siegal, F. P., C. Lopez, G. S. Hammer, A. E. Brown, S. J. Kornfeld, J. Gold, J. Hassett, S. Z. Hirschman, C. Cunningham-Rundles, B. R. Adelsberg, D. M. Parham, M. Siegal, S. Cunningham-Rundles, and D. Armstrong. 1981. Severe acquired immunodeficiency in male homosexuals manifested by chronic perianal ulcerative herpes simplex lesions. N. Engl. J. Med. 305:1439-1444. 